\title{
Antimicrobial Effect of Lactobacillus reuteri on Cariogenic Bacteria Streptococcus gordonii, Streptococcus mutans, and Periodontal Diseases Actinomyces naeslundii and Tannerella forsythia
}

\author{
Magda Lorena Baca-Castañón • Myriam Angélica De la Garza-Ramos • \\ Andrea Guadalupe Alcázar-Pizaña • Yohann Grondin • Anahí Coronado-Mendoza • \\ Rosa Isela Sánchez-Najera • Eloy Cárdenas-Estrada • Carlos Eduardo Medina-De la Garza • \\ Erandi Escamilla-García \\ (C) Springer Science+Business Media New York 2014
}

\begin{abstract}
Lactic acid bacteria (LAB) are well known for their beneficial effects on human health in the intestine and immune system; however, there are few studies on the impact they can generate in oral health. The aim of this study was to test and compare in vitro antimicrobial activity of $L$. reuteri on pathogenic bacteria involved in the formation of dental caries: S. mutans, S. gordonii, and periodontal disease: A. naeslundii and T. forsythia. Also, we determined the growth kinetics of each bacterium involved in this study. Before determining the antimicrobial action of $L$. reuteri on cariogenic bacteria and periodontal disease, the behavior and cell development time of each pathogenic bacterium were studied. Once the conditions for good cell growth of each of selected pathogens
\end{abstract}

Magda Lorena Baca-Castañón and Myriam Angélica De la GarzaRamos are first authors.

M. L. Baca-Castañón · M. A. De la Garza-Ramos ·

A. G. Alcázar-Pizaña · A. Coronado-Mendoza

E. Escamilla-García $(\square)$

Unidad de Odontología Integral y Especialidades, Centro de Investigación y Desarrollo en Ciencias de la Salud (CIDICS), Universidad Autónoma de Nuevo León (UANL), Ave. Carlos Canseco s/n con Ave. Gonzalitos, Mitras Centro,

CP: 64460 Monterrey, Nuevo León, Mexico

e-mail: erandi.escamillagrc@uanl.edu.mx

M. L. Baca-Castañón · M. A. De la Garza-Ramos .

A. G. Alcázar-Pizaña · R. I. Sánchez-Najera ·

E. Escamilla-García

Departamento de Microbiología, Facultad de Odontología,

Universidad Autónoma de Nuevo León (UANL), Monterrey,

Nuevo León, Mexico

Y. Grondin

Facultad de Ciencias Biológicas, Universidad Autónoma de

Nuevo León, San Nicolás de los Garza, Nuevo León, Mexico were established according to their metabolic requirements, maximum exponential growth was determined, this being the reference point for analyzing the development or inhibition by LAB using the Kirby Bauer method. Chlorhexidine $0.12 \%$ was positive control. L. reuteri was shown to have an inhibitory effect against $S$. mutans, followed by $T$. forsythia and S. gordonii, and a less significant effect against $A$. naeslundii. Regarding the effect shown by $L$. reuteri on the two major pathogens, we consider its potential use as a possible functional food in the prevention or treatment of oral diseases.

Keywords Lactobacillus reuteri . Probiotic . Cariopathogens - Periopathogens - Bacterial inhibition . Oral health

\footnotetext{
E. Cárdenas-Estrada

Unidad de Ensayos Clínicos, Centro de Investigación y

Desarrollo en Ciencias de la Salud (CIDICS), Universidad Autónoma de Nuevo León (UANL), Ave. Carlos Canseco s/n con Ave. Gonzalitos, Mitras Centro, CP: 64460 Monterrey, Nuevo León, Mexico

C. E. Medina-De la Garza

Unidad de Inmunomoduladores, Centro de Investigación y Desarrollo en Ciencias de la Salud (CIDICS), Universidad Autónoma de Nuevo León (UANL), Ave. Carlos Canseco s/n con Ave. Gonzalitos, Mitras Centro, CP: 64460 Monterrey, Nuevo León, Mexico

C. E. Medina-De la Garza

Departamento de Inmunología, Facultad de Medicina,

Universidad Autónoma de Nuevo León, Monterrey,

Nuevo León, Mexico
} 


\section{Introduction}

The oral cavity microbiota is an ecosystem formed nearly by 700 different microbial species [1]. This complex system can be altered by diverse factors, including poor hygiene and diet, smoking, stress and systemic diseases [2]. All these perturbations favor the colonization by pathogenic bacteria and the formation of biofilms, which are both etiological factors of periodontal diseases. Identified pathogenic bacteria, including Streptococcus gordonii [3], Actinomyces naeslundii [4], and Tannerella forsythia $[5,6]$, contribute differently to the onset of periodontal diseases. For example, early colonization of $S$. gordonii, one of the most abundant microorganisms in dental plaques [7], is essential for further colonization by other bacterial strains and biofilm formation as it produces bacterial growth-enabling adherence substrates [8]. Other bacteria such as A. naeslundii affect the cervical areas of the teeth and supporting tissues [9] and have been specifically implicated in the development of caries on root surfaces [4]. Finally, T. forsythia, which is found at the active sites of infection, has been associated with advanced and recurrent periodontitis [10].

Controlling the colonization of the oral cavity by pathogenic bacteria is essential for the prevention of periodontal diseases. Studies in that respect have been focusing on a class of nonpathogenic microorganisms called probiotics [11] among which Gram-positive lactic acid bacteria (LAB) are most promising candidates. The potential health benefits of these LAB are multiple, from stimulating the immune system, maintaining the intestinal microflora balance, competing with pathogens, reducing childhood allergies to controlling hyperlipidemia and/or liver disease [12]. For example, a mix of L. acidophilus and L. casei enhances the effect of anticancer drug 5-fluorouracil by increasing apoptosis of colorectal cancer cell line LS513 in vitro $[13,14]$.

Most interesting for the control of periodontal diseases is $\mathrm{LAB}$, with antimicrobial and anti-inflammatory properties such as $L$. reuteri, L. fermentum, and $L$. casei Shirota $[15,16]$. Of these bacteria, $L$. reuteri is most interesting for the control of oral microbiota as it produces reuterin, a wide spectrum antimicrobial agent [17]. Reuterin inhibits growth of both Gram-positive and Gram-negative bacteria, including oral pathogens $S$. mutans, Actinomyces actinomycetemcomitans, Prevotella intermedia, Fusobacterium nucleatum, as well as yeasts like Candida albicans, some fungi and protozoa [18-20].

Some studies have shown promising results on the inhibition by $L$. reuteri isolated from humans and rats of both the growth of various oral pathogens, including T. forsythia, and biofilm formation [21]. Even more interesting is that antimicrobial property of $L$. reuteri appearing to be maintained when food products are used as a vector for their delivery. Çaglar et al. [22] reported in in vivo studies that levels of $S$. mutans in saliva were positively reduced without antagonistic effects in the presence of $L$. reuteri contained in tablets at a concentration of $1 \times 10^{9} \mathrm{CF} \mathrm{U} / \mathrm{mL}$. Another study [23] showed that consumption of yogurts containing $L$. reuteri at different concentrations reduced $S$. mutans in the oral cavity.

In this study, we determined the in vitro antimicrobial action of $L$. reuteri on pathogens associated with the formation of dental caries, S. gordonii and S. mutans, and with the development of periodontal diseases, A. naeslundii and T. forsythia.

\section{Materials and Methods}

Kinetics was assessed prior to the Kirby Bauer method, in particular, the determination of lag and exponential phase. The time required for both the LAB and the odontopathogenic bacteria to reach their maximum exponential growth was fundamental to testing the inhibitory effect of Lactobacillus reuteri ATCC55730 by the Kirby Bauer method.

\section{Biological Material}

Four strains of pathogenic oral bacteria were selected for this study: S. gordonii (ATCC10558), Streptococcus mutans UA130 (ATCC700611), Tanarella forsythia (ATCC4 3037), and A. naeslundii (ATCC51655). Culture and growth conditions for each bacterium were based on the technical sheets of the American Type Culture Collection (ATCC) (Table 1).

Table 1 Media and culture conditions for organisms used as established by the American Type Culture Collection (ATCC)

\begin{tabular}{|c|c|c|c|}
\hline Bacterium & $\begin{array}{l}\text { Pre-culture-Culture } \\
\text { media (agar-broth) }\end{array}$ & Atmosphere & $\begin{array}{l}\text { Incubation } \\
\text { time at } \\
37^{\circ} \mathrm{C}(\mathrm{h})\end{array}$ \\
\hline $\begin{array}{l}\text { Lactobacillus } \\
\text { reuteri }\end{array}$ & MRS-MRS & Anaerobic & $24-48$ \\
\hline $\begin{array}{l}\text { Streptococcus } \\
\text { gordonii }\end{array}$ & TS-BHI & Aerobic & 24 \\
\hline $\begin{array}{l}\text { Streptococcus } \\
\text { mutans }\end{array}$ & BHI-BHI & Aerobic & $24-48$ \\
\hline $\begin{array}{l}\text { Tanerella } \\
\text { forsythia }\end{array}$ & $\begin{array}{l}\text { NAM-PY media with } \\
\text { Horse serum and } \\
\text { NAM }\end{array}$ & Anaerobic & $24-48$ \\
\hline $\begin{array}{c}\text { Actinomyces } \\
\text { naeslundii }\end{array}$ & $\begin{array}{l}\text { CAMG medium } \\
\text { pH } 7.5( \pm 0.1)\end{array}$ & Anaerobic & $24-48$ \\
\hline
\end{tabular}




\section{Growth Conditions}

Specific pre-culture on agar in Petri dishes was performed for the bacteria for $24-48 \mathrm{~h}$ at $37^{\circ} \mathrm{C}$ (Thermo Scientific Incubator Lab-Line, Marietta, OH); as indicated by ATCC. $L$. reuteri and two of the Gram-negative oral pathogens, $T$. forsythia and A. naeslundii are anaerobes and their handling requires a controlled atmosphere in an anaerobic chamber (Plas-Labs, Lansing/MI). This atmosphere was a mixture of $\mathrm{H}_{2}(20.13 \%), \mathrm{CO}_{2}(10.13 \%)$, and $\mathrm{N}_{2}$ $(69.74 \%)$ gas (Praxair/Mexico). All culture media as well as the material were pre-sterilized $15 \mathrm{~min}$ at $120{ }^{\circ} \mathrm{C}$ (AllAmerican, Hillsville, USA). Broth culture were carried out in $250-\mathrm{mL}$ flasks containing $200 \mathrm{~mL}$ of culture medium as appropriate for each microorganism (see Table 1) and inoculated to an optical density (OD) of 0.2 at $600 \mathrm{~nm}$. Prior to inoculation, pre-culture was washed with normal saline $(0.9 \% \mathrm{w} / \mathrm{v}$ of $\mathrm{NaCl})$.

The culture medium used for $L$. reuteri is based on requirements indicated by the ATCC with suitable growth conditions. The original strain was lyophilized and frozen at $-80{ }^{\circ} \mathrm{C}$. Activation was done by inoculating Man Rogosa and Sharpe (MRS) broth (BD-Difco, BectonDickinson and Company, Pont-de-Claix/France). For subsequent activations from a broth culture, $15 \mathrm{~g} / \mathrm{L}$ of agar was added (Becton-Dickinson and Company).

Tannerella forsythia was previously grown on $N$-acetyl muramic acid agar [24] (Sigma-Aldrich, St. Louis/MO) that consists of $49 \mathrm{~g}$ tryptone soy agar (Becton-Dickinson and Company), and $10 \mathrm{~mL}$ of hemin (AppliChem GMbH, Darmstadt/Germany) suspended in $1 \mathrm{~L}$ of distilled water. It was subsequently grown in peptone-yeast (PY) comprised (g/L) of 5-peptone (Dibico/Mexico), 5-tryptone (BioBasicInc.), 10-yeast extract (Dibico), $4 \mathrm{~mL}$ of resazurin, $40 \mathrm{~mL}$ of water or normal saline, $10 \mathrm{~mL}$ of hemin, $0.2 \mathrm{~mL}$ of vitamin K, 0.5 L-cysteine (Sigma-Aldrich), and pH $7.0( \pm 0.1)$.

Actinomyces naeslundii also requires a specific medium, this being CAMG composed of (g/L) 5-tryptone, 5-yeast extract (Dibico), 5- $\mathrm{K}_{2} \mathrm{HPO}_{4}$, 2-glucose (Jalmek-Científica/ Mexico), and $0.5 \mathrm{~mL}$ polysorbate $80, \mathrm{pH} 7.5( \pm 0.1)$. The development of both microorganisms was carried out in a controlled gas mixture atmosphere at $37^{\circ} \mathrm{C}$ for $24-48 \mathrm{~h}$.

Streptococcus mutans required pre-culture in tryptone soy agar and cultured in Brain Heart Infusion broth (both from BD Bioxon, Becton-Dickinson and Company), while BHI was used for S. gordonii, in both inocula (Table 1). Incubation was performed at $37{ }^{\circ} \mathrm{C}$ for both strains for $24 \mathrm{~h}$ for $S$. gordonii and $24-48 \mathrm{~h}$ for $S$. mutans.

The morphology of the strains was confirmed by growth on agar (Petri dish) and by microscopy using differential staining (Gram; data not shown). An inverted fluorescence microscope (Axio Inverter Z.1, Carl Zeiss-AG/Germany) was used.
Growth Kinetics

To determine the doubling time and specific growth rate of each bacteria, we used a bacterial cell suspension with a McFarland standard $2.0\left(\mathrm{OD}_{600 \mathrm{~nm}}=0.2-0.5\right)$ determined with a Genesys 10 UV Scanning Spectrophotometer (Thermo-Scientific, Madison/WI). Three 250-mL flasks containing $200 \mathrm{~mL}$ of appropriate culture medium were inoculated (Table 1) and incubated at $37^{\circ} \mathrm{C}$ for $3 \mathrm{~min}$ for further adaptation of cells to culture conditions. Then a first sample was taken, which represents time zero. Development was monitored by taking samples and measuring the OD $(600 \mathrm{~nm})$ and $\mathrm{pH}$ (Ulltrabasic-Potentiometer, DenverInstruments, Arvada/CO) every $3 \mathrm{~h}$ during $72 \mathrm{~h}$ for $L$. reuteri culture and every hour during $25-30 \mathrm{~h}$ for $S$. gordonii, S. mutans, T. forsythia, and A. naeslundii. Growth kinetics was performed in duplicate for all bacterial strains.

Doubling time (h) and specific growth rate $\left(\mu=\mathrm{h}^{-1}\right)$ were calculated from the exponential growth phase for each bacterium.

\section{Inhibitory Effect of Lactobacillus reuteri}

\section{Kirby Bauer Method}

The Kirby Bauer method is performed to study the activity of antimicrobial agents against pathogenic microorganisms [25]; in this case, L. reuteri was the agent to show antimicrobial activity. This method is based on the formation of growth inhibition zones around disks made of filter paper impregnated with the antimicrobial agent. For this study, the Kirby Bauer method was made inside an anaerobic chamber because anaerobic conditions are required for $L$. reuteri. As previously described, the pathogenic bacteria are inoculated in a Petri dish that has the appropriate bacterial agar forming a monolayer. A disk is subsequently immersed in the culture that contains the LAB ( $L$. reuteri) and is placed in the Petri dish. All pathogens selected for the study were previously activated, and each was taken in their exponential phase according to the results previously obtained in growth kinetics.

To determine the antimicrobial effect of $L$. reuteri, Chlorhexidine-digluconate $0.12 \%$ (CHX, Consepsis Ultradent Products/Inc., South Jordan/UT), an antiseptic agent used in dentistry as a mouthwash or mouth rinse, was used as inhibition positive control and to establish a reference of the effect of $L$. reuteri on oral pathogens and sterile distilled water as a negative control. Both controls were handled in the same way as $L$. reuteri, and all the procedures were performed in triplicate. Finally, the Petri dishes containing the respective antibiograms were incubated at $37{ }^{\circ} \mathrm{C}$ for $24 \mathrm{~h}$ to determine the presence or absence of the halos formed around the disk. 
Evaluation of the Kirby Bauer method was performed in a qualitative manner by formation of inhibition zones at the periphery of the disk, both for the sample of interest and its controls. Then a quantitative analysis is made by measuring the diameter of the inhibition halo formed for each condition. The result was an indicator of the efficiency of antimicrobial agent (L. reuteri) against selected pathogenic bacteria.

\section{Statistical Analysis}

Three independent replicates of each experiment were performed, and their results were expressed as mean diameter \pm standard deviation (SD). We used data analysis, and the significances of the inhibitory effect of $L$. reuteri against $\mathrm{CHX}$ were evaluated with unequal variance analysis based on the *t test and the **Mann-Whitney $(P<0.05)$ test and calculated with statistical software, STATA-13, Serial-Nr. 1910531247

\section{Results}

Bacterial morphology and differentiation were confirmed for each oral pathogen selected in this study by standard stains and cultures (data not shown).

\section{Growth Kinetics}

The results presented correspond to the mean value of each experiment.

Lactobacillus reuteri showed the typical phases of microbial growth. The lag phase lasted $8 \mathrm{~h}$ with no change in $\mathrm{OD}_{600 \mathrm{~nm}}: 0.12 \pm 0.01$ (Fig. 1) and a pH of $6.45 \pm 0.10$; at this time, exponential growth phase begins and lasts up to $18 \mathrm{~h}$, where maximum growth occurs with an OD of $1.77 \pm 0.02$ and a $\mathrm{pH} 4.10 \pm 0.10$. After this time, stationary phase is established with an OD of $1.8 \pm 0.10$ and a pH $4.29 \pm 0.13$.

The Gram-positive, cariogenic bacteria are seen in Fig. 2a. S. mutans, with only $2 \mathrm{~h}$ from start of culture with

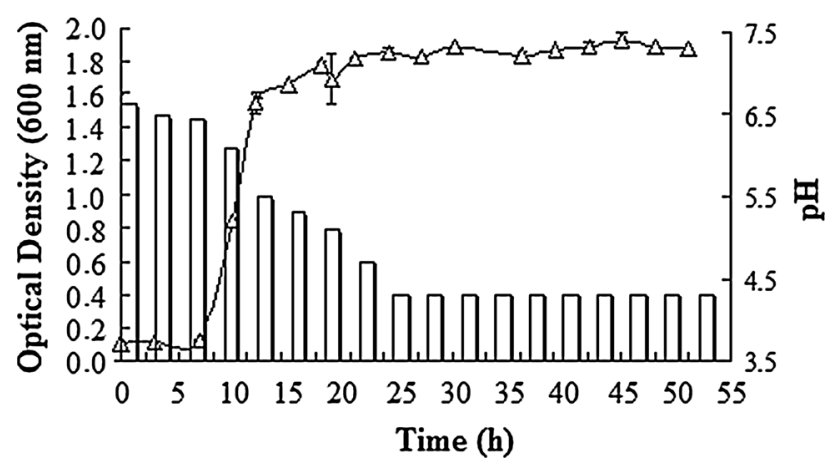

Fig. 1 Growth kinetics (triangle) and $\mathrm{pH}$ (white bar) of L. reuteri a pH $7.14 \pm 0.01$ (Fig. 2a.1), presented exponential growth reaching its peak in $5 \mathrm{~h}$ with an OD of $1.15 \pm 0.05$ and a $\mathrm{pH} 5.83 \pm 0.0$. After this time, growth remained constant until about $17 \mathrm{~h}$ maintaining a pH $6.185 \pm 0.13$.

Streptococcus gordonii has a different behavior than $S$. mutans. It has no lag phase at inoculation, and logarithmic growth reaches its maximum peak of development at $7 \mathrm{~h}$ with an OD of $1.4 \pm 0.05$ and a pH $4.99 \pm 0.01$ (Fig. 2a.1); the stationary phase is then established for a long period of time (over $20 \mathrm{~h}$ ).

The Gram-negative, periodontopathogenic bacteria are seen in Fig. 2b. A. naeslundii grows slowly with an initial pH $6.7 \pm 0.04$ (Fig. 2b.1), and a lag phase of about 14 h; afterward, exponential growth starts with a duration of just $3 \mathrm{~h}$, reaching its maximum $\mathrm{OD}$ of 0.5 and a $\mathrm{pH}$ $5.38 \pm 0.03$ at $17 \mathrm{~h}$ of incubation. Then the stationary phase remains constant up to $22 \mathrm{~h}$, maintaining a $\mathrm{pH}$ $5.34 \pm 0.03$. $T$. forsythia grew very quickly, with a very short lag phase. The start of the logarithmic phase occurred almost immediately, reaching its peak in $5 \mathrm{~h}$ with an OD of $0.87 \pm 0.1$ and a pH $5.47 \pm 0.01$ (Fig. 2b.1). Subsequently, the stationary phase was established at about $19 \mathrm{~h}$.

\section{Doubling Time and Specific Growth Rate}

The doubling time and specific growth rate (Fig. 3) were determined and analyzed for each microorganism prior to assessing the antimicrobial activity of $L$. reuteri. Of all bacteria, growth kinetics showed that the doubling time was the shortest for $S$. mutans at $0.86 \pm 0.03 \mathrm{~h}$ and the longest for $S$. gordonii and $L$. reuteri at about $3 \mathrm{~h}$. Remaining bacteria $A$. naeslundii and T. forsythia showed intermediate doubling times of $2 \mathrm{~h}$.

In general, these values were confirmed with the determination of the specific growth rate $(\mu)$, this still being very high from $S$. mutans compared with other microorganisms $0.81 \pm 0.03 \mathrm{~h}^{-1}$. L. reuteri and $S$. gordonii presented very similar specific growth rate (slower compared with studied bacteria), with values of $\mu=0.24 \pm 0.01 \mathrm{~h}^{-1}$ and $\mu=0.23 \pm 0.04 \mathrm{~h}^{-1}$, respectively. On the other hand, $A$. naeslundii has a $\mu$ of $0.32 \pm 0.00 \mathrm{~h}^{-1}$ and a value of $0.34 \pm 0.03 \mathrm{~h}^{-1}$, from $T$. forsythia.

Inhibitory Effect of L. reuteri

The result of each kinetic, specifically the time required for both the LAB and the odontopathogenic bacteria to reach their maximum exponential growth, was utilized to determine the inhibitory effect of $L$. reuteri by the Kirby Bauer method.

The inhibitory halos around the disk impregnated with $L$. reuteri during their peak log-growth $(16 \mathrm{~h})$ were measured $(\mathrm{mm})$ to determine the activity of $L$. reuteri against bacteria. Results of measurement of inhibition halos of 


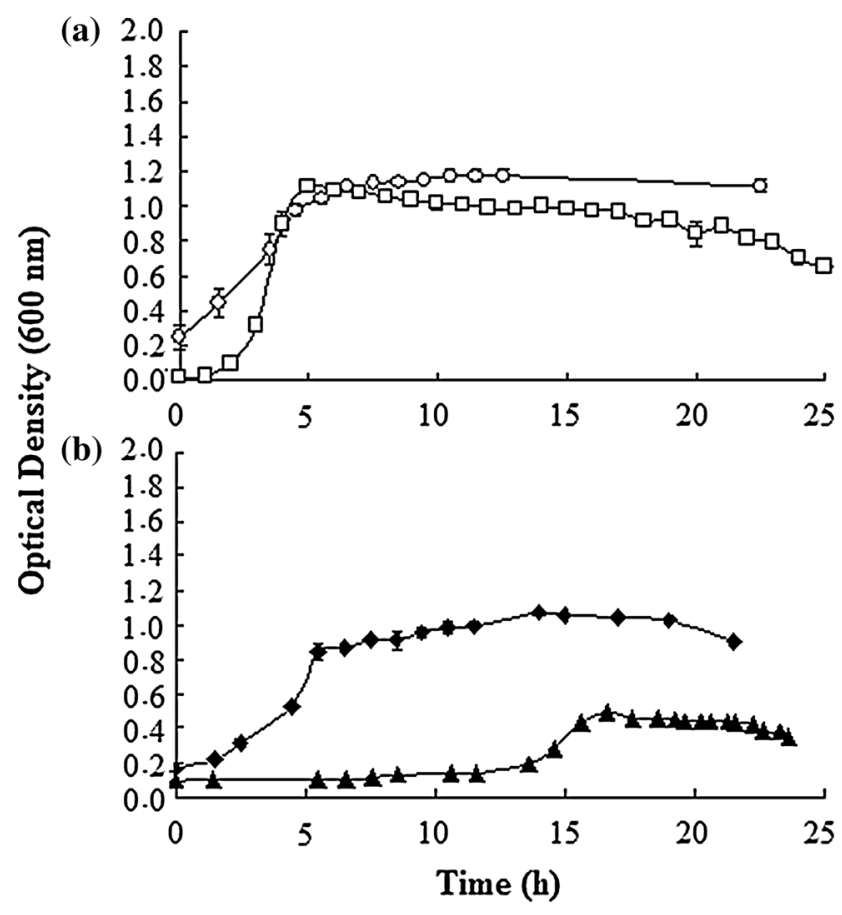

Fig. 2 Growth kinetics and $\mathrm{pH}$ values (represented in bar) of oral pathogenic bacteria in dental caries (a, a.1): S. gordonii (open circle, striped bar) and $S$. mutans (open square, open bar), and periodontal

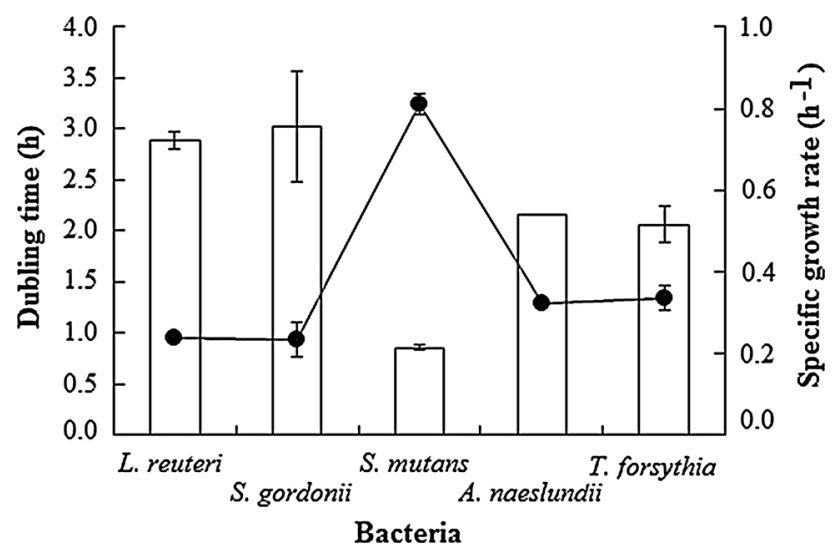

Fig. 3 Doubling time (histogram) and specific growth rate (filled circle) determined for each tested bacterial strain. Data are given as mean diameter \pm standard deviation

both LAB and Chlorhexidine (CHX, as a positive control) are shown in Fig. 4. L reuteri had a growth inhibitory activity against three of the pathogenic bacteria used, showing different inhibition halos against each one. Thus, the larger halos were observed against $S$. mutans, $S$. gordonii, and T. forsythia $(10.3 \pm 0.81,7.3 \pm 5.68$ and $8.5 \pm 0.54 \mathrm{~mm}$, respectively), while to A. naeslundii, the inhibition halo was small $(5.8 \pm 4.53 \mathrm{~mm})$. With CHX, the halos were $13.83 \pm 2.13,12.83 \pm 3.18,15.66 \pm 3.50$, and $6.83 \pm 5.38 \mathrm{~mm}$, against $S$. mutans, $S$. gordonii, and T. forsythia, respectively. Again, the inhibition halo of $A$.

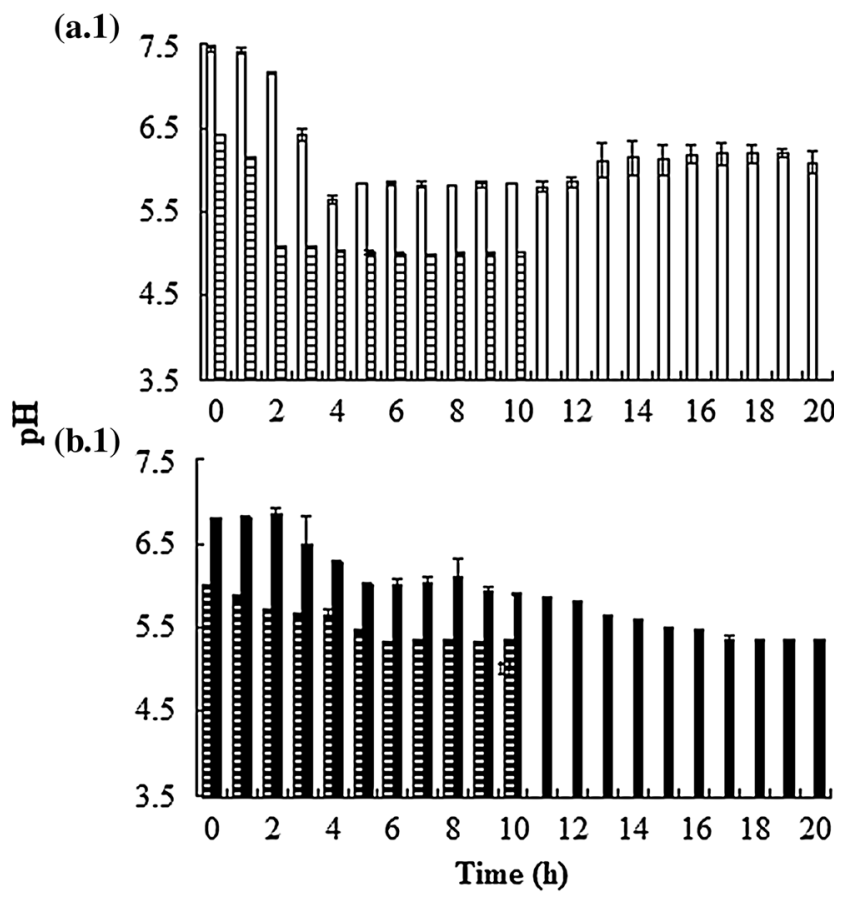

disease (b, b.1): A. naeslundii (filled triangle, filled bar) and T. forsythia (filled diamond, filled striped bar)

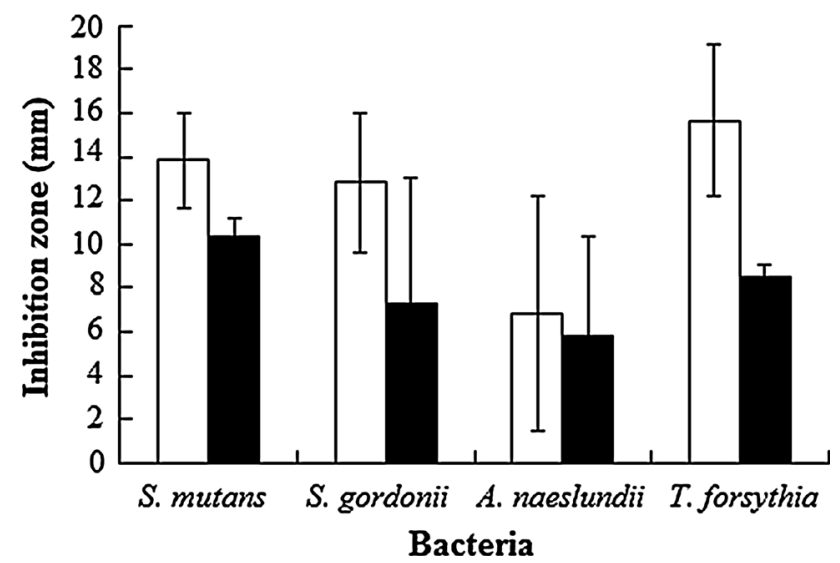

Fig. 4 Determination of bacterial susceptibility of $S$. mutans and $S$. gordonii (present in dental caries) and A. naeslundii and T. forsythia (in periodontal disease), to L. reuteri (filled square) and Chlorhexidine (open square), as antimicrobial compounds

naeslundii was smaller than other pathogens, thus showing resistance to CHX, as happened with $L$. reuteri.

\section{Discussion}

The trend in recent years is the search for new antimicrobial substances that can be used as an alternative to the existing ones and that are safe, in this respect, the LAB are 
very promising candidates because of its well-known health effect. In the search for therapeutic options, $L$. reuteri could be a possible biological alternative for prevention or treatment of oral diseases. This study demonstrates the sensitivity of three major oral pathogens that cause caries or periodontal disease to the probiotic $L$. reuteri. Finally, analysis of bacterial growth is of great interest in dental and general health since it contributes to the understanding of microbial processes and their impact on oral health.

The first part of this study include the growth kinetics of each of the microorganisms involved, in determining the doubling time and specific growth rate of each bacterium, important parameters for analysis of the inhibitory effect of L. reuteri by the Kirby Bauer method, because it is important that microorganisms are more active metabolically.

Regarding pathogenic bacteria, growth kinetics were very different among them. It should be noted that some of these bacteria are specific for damaging hard structures, like teeth enamel, while others damage soft structures, such as those of the oral cavity. The biggest and best protective effect of a microorganism or aggression is caused when they are metabolically active, a phenomenon that occurs during maximum exponential growth. Knowledge of this phase in the kinetics of each pathogen lets us understanding better the time that each one needs to cause damage to soft tissues by degrading collagen present in periodontal ligament, altering $\mathrm{pH}$ conditions in oral cavity creating an ideal microenvironment for A. naeslundii, T. forsythia growth. However, in hard structures, S. mutans and S. gordonii, for example, produce organic acids as a result of their carbohydrate metabolism, causing enamel demineralization. These data give us more information on the behavior and growth of pathogen to implement more studies about a biological agent, which prevents their proliferation and maybe irreversible damage on some structures of the oral cavity. With respect to growth, the duration of the lag phase differed greatly between pathogenic bacteria, from a few hours or less for $T$. forsythensis, S. gordonii, and $S$. mutans, to $14 \mathrm{~h}$ for $A$. naeslundii (Fig. 2). The lag phase for $L$. reuteri is then considered as intermediate.

There are some reports on the growth of these bacteria, although strains and culture media may differ to a point where growth kinetics is altered [21]. For example, $L$. reuteri isolated from human feces to treat against pathogenic gastrointestinal bacteria presented a similar slow growth dynamics as the one reported here [26]. However, it is possible to achieve a much shorter lag phase and higher growth rate, as shown with $L$. reuteri PRO 137 strain suspended in glycerol solution [27]. Our data are consistent with those observed in both studies.

When $S$. mutans is grown in anaerobic conditions, there is an absence of a lag phase and the exponential phase is stable for $8 \mathrm{~h}$ [21]. Other authors report the behavior of the same bacteria during biofilm formation on the surface of female rat teeth. Two hours after inoculation of the bacteria, growth declined due to the presence of sucrose, and the logarithmic growth phase occurred reaching its maximum exponential point at $6 \mathrm{~h}$ [28].

On the other hand, there are no reports in the literature on the growth of cariogenic bacteria S. gordonii. Data exist only on biofilm formation and its adhesion to tooth surfaces with the addition of carbon sources (glucose/sucrose), in which different stages of adaptation, prevalence, and biofilm structure development appear [29].

About the Gram-negative periodontopathogenic bacteria, particularly with $A$. naeslundii, no previous reports on growth stages were found. On the other side, Kang et al. [21] used the same T. forsythia strain as in this study; however, the lag phase lasted $8 \mathrm{~h}$ with a slower rate of growth.

With these data, we can conclude that at least two of the cariogenic bacteria selected for the study are very different in their growth, which would explain the ability of $S$. mutans to form biofilm. Development of this biofilm requires that other microbial sources help it establish on the surface of teeth and cause damage. It may also contain genetic material and metabolites that are easier to synthesize for division and generation of two identical daughter cells. However, we must not forget that conditions of culture medium and incubation are important factors for early or slow development. Logarithmic phase of each bacterium was considered to test the inhibitory effect of $L$. reuteri because microorganisms are most active and begin the process of division in this stage. The log phase is generally quite rapid and puts the bacterial cells in a vulnerable position in the possibility to be more pathogen or effective as the case.

Antibiograms are widely used to test inhibition of microbial growth. Asikainen [30] used antibiograms to evaluate the effect of $L$. reuteri on pathogenic bacteria from periodontal tissue, such as A. actinomycetemcomitans, $P$. intermedia, and $F$. nucleatum, obtaining favorable results in the inhibition of these pathogens. In our study, a significative difference between the inhibition halo formed by $L$. reuteri and CHX for both $S$. mutans and $T$. forsythia $\left({ }^{*} P=0.004\right.$ and $\left.{ }^{* *} P=0.001\right)$ was observed. On the other hand, no significant difference between the effect of LAB and CHX against $S$. gordonii and A. naeslundii was found $(* P=0.065$ and $* * P=0.073)$.

Çaglar et al. [22] reported in vivo studies where numbers of $S$. mutans in saliva were positively reduced without antagonistic effects in the presence of $L$. reuteri, administered in the form of chewing tablets at a concentration of $1 \times 10^{9} \mathrm{CFU} / \mathrm{mL}$. Another study by Nikawa et al. [23] revealed that consumption of yogurt containing $L$. reuteri 
in different concentrations reduced $S$. mutans in the oral cavity. They pointed out that $L$. reuteri was three times more effective than other lactobacilli and reported a mortality of $90 \%$ for $S$. mutans. Other studies performed with the same LAB applied to various pathogens in the oral cavity (C. albicans, S. mutans, Actinomyces actinomycentemcomitans, P. intermedia, F. nucleatum, etc.) and/or the gastrointestinal tract (E. coli, Salmonella, Shigella, Proteus, Pseudomonas, Clostridium, S. aureus, yeast, fungi, protozoa, viruses) as Connolly showed [17].

Similar studies about reduction of $S$. mutans and periodontal pathogens, but with other LAB, concern different species of Lactobacillus paracasei. L. paracasei GMNL-33 is proposed as a strategy for caries prevention and management [31]. L. paracasei DSMZ16671 was used in a pilot study under the form of sugar-free candies, showing that their consumption reduces up to $86.6 \%( \pm 0.1)$ of $S$. mutans in human saliva [32]. Administration of L. paracasei in foods, oral hygiene, or oral treatment medicine can inhibit or reduce the number of pathogens of dental caries (S. mutans, S. sobrinus) and periodontal diseases ( $P$. gingivalis, $P$. intermedia), in oral cavity of the user [33].

The inhibition assays in this study were performed only with the microorganism and not with the active substance, (reuterin). Therefore, we may expect the possibility of an increased antimicrobial effect against these dental plaque bacteria with the use of the active substance alone, and this possibility is currently on testing in our laboratory. Even the difference in sensitivity expressed by $S$. mutans, $S$. gordonii, and $T$. forsythia to the action of L. reuteri may represent a promising and interesting biological and natural alternative in the treatment and/or prevention of oral diseases. Thus, continuous study and testing of its antimicrobial effect at different concentrations and recognition of its activity spectrum represent an area for active and ongoing research. A major target is $S$. gordonii, a bacteria considered an initial colonizer in the oral cavity and responsible for the establishment of other microorganisms with more pathogenic potential. To date, there is little information on the mechanism of action of $L$. reuteri on other pathogenic microorganisms, but it appears that reuterin acts on thiol groups of proteins, causing oxidative stress [34]. Based on our results, we suggest an extended study of $L$. reuteri for a deeper knowledge on its antibacterial properties, to allow its proposal as a supplement in the agri-food area, as a probiotic contributing to maintain a good oral health and avoid caries or periodontal infections.

Acknowledgments This work was partly funded by a Grant from the Ministry of Public Education of Mexico, under the PROMEP program, Registration No. UANL-PTC-367 and by the Support Program for Scientific and Technological Research (PAICYT-UANL) No. CN 802-11. We particularly thank Suarez-Martínez VR for technical assistance in managing the anaerobic chamber. Dr. Med.
Cardenas-Estrada E (CIDICS), who performed the statistical analysis of this study.

Conflict of interest M. L. Baca-Castañón, M. A. De la GarzaRamos, A. G. Alcázar-Pizaña, Y. Grondin, A. Coronado-Mendoza, R. I. Sánchez-Najera, E. Cárdenas-Estrada, C. E. Medina-De la Garza and E. Escamilla-García declare that they have no conflict of interests.

\section{References}

1. Kuramitsu HK, He X, Lux R, Anderson MH, Shi W (2007) Interspecies Interactions within oral microbial communities. Microbiol Mol Biol Rev 71:653-670. doi:10.1128/MMBR. 00024-07

2. Milward MR, Chapple ILC (2013) The role of diet in periodontal disease. Clin Dent Health 52:18-21

3. Hendrickson EL, Wang T, Dickinson BC, Whitmore SE, Wright CJ, Lamont RJ, Hackett M (2012) Proteomics of Streptococcus gordonii within a model developing oral microbial community. BMC Microbiol 12:1-23. doi:10.1186/1471-2180-12-211

4. Borssén E, Sundqvist G (1981) Actinomyces of infected dental root canals. Oral Surg Oral Med Oral Pathol 51:643-648. doi:10. 1016/S0030-4220(81)80016-3

5. Haffajee AD, Cugini MA, Tanner A, Pollack RP, Smith C, Kent RL, Socransky SS (1998) Subgingival microbiota in healthy, well-maintained elder and periodontitis subjects. J Clin Periodontol 25:346-353. doi:10.1111/j.1600-051X.1998.tb02454.x

6. Macuch PJ, Tanner ACR (2000) Campylobacter species in health, gingivitis, and periodontitis. J Dent Res 79:785-792. doi:10. 1177/00220345000790021301

7. Loo CY, Corliss DA, Ganeshkumar N (2000) Streptococcus gordonii biofilm formation: identification of genes that code for biofilm phenotypes. J Bacteriol 182:1374-1382. doi:10.1128/jb. 182.5.1374-1382.2000

8. Plummer C, Douglas CWI (2006) Relationship between the ability of oral streptococci to interact with platelet glycoprotein $\mathrm{Ib} \alpha$ and with the salivary low-molecular-weight mucin, MG2. FEMS Immunol Med Microbiol 48:390-399. doi:10.1111/j.1574695X.2006.00161.x

9. Zylber LJ, Jordan HV (1982) Development of a selective medium for detection and enumeration of Actinomyces viscosus and Actinomyces naeslundii in dental plaque. J Clin Microbiol 15:253-259

10. Lai CH, Listgarten MA, Shirakawa M, Slots J (1987) Bacteroides forsythus in adult gingivitis and periodontitis. Oral Microbiol Immun 2:152-157. doi:10.1111/j.1399-302X.1987.tb00299.x

11. Ambalam PS, Prajapati JB, Dave JM, Nair BM, Ljungh $\AA$, Vyas BRM (2009) Isolation and characterization of antimicrobial proteins produced by a potential probiotic strain of human Lactobacillus rhamnosus 231 and its effect on selected human pathogens and food spoilage organisms. Microb Ecol Health Dis 21. doi:10.3109/08910600903429052

12. Brown AC, Valiere A (2004) Probiotics and medical nutrition therapy. Nutr Clin Care 7:56-68

13. Baldwin C, Millette M, Oth D, Ruiz MT, Luquet FM, Lacroix M (2010) Probiotic Lactobacillus acidophilus and Lactobacillus casei mix sensitize colorectal tumoral cells to 5-fluorouracilinduced apoptosis. Nutr Cancer 62:371-378. doi:10.1080/ 01635580903407197

14. Bujňáková D, Kmeť V (2012) Functional properties of Lactobacillus strains isolated from dairy products. Folia Microbiol 57:263-267. PMCID: PMC1482314

15. Hernandez-Mendoza A, Guzmán-de-Peña D, García HS (2009) Key role of teichoic acids on aflatoxin $\mathrm{B} 1$ binding by probiotic 
bacteria. J Appl Microbiol 107:395-403. doi:10.1111/j.13652672.2009.04217.x

16. Sánchez-Maldonado AF, Schieber A, Gänzle MG (2011) Structure-function relationships of the antibacterial activity of phenolic acids and their metabolism by lactic acid bacteria. J Appl Microbiol 111:1176-1184. doi:10.1111/j.1365-2672.2011.05141.x

17. Connolly E (2004) Lactobacillus reuteri ATCC 55730: a clinically proven probiotic. NUTRAfoods $3: 15-22$

18. Dobrogosz WJ (2005) Enhancement of human health with Lactobacillus reuteri. NUTRAfoods 4:15-28

19. Savino F, Pelle E, Palumeri E, Oggero R, Miniero R (2007) Lactobacillus reuteri (American Type Culture Collection Strain 55730) versus simethicone in the treatment of infantile colic: a prospective randomized study. Pediatrics 119:124-130. doi:10. 1099/mic.0.035642-0

20. Talarico TL, Dobrogosz WJ (1989) Chemical characterization of an antimicrobial substance produced by Lactobacillus reuteri. Antimicrob Agents Chemother 33:674-679. doi:10.1128/aac.33.5.674

21. Kang MS, Oh JS, Lee HC, Lim HS, Lee SW, Yang KH, Choi NK, Kim SM (2011) Inhibitory effect of Lactobacillus reuteri on periodontopathic and cariogenic bacteria. J Microbiol 49:193-199. doi:10.1007/s12275-011-0252-9

22. Çaglar E, Cildir SK, Ergeneli S, Sandalli N, Twetman S (2006) Salivary mutans streptococci and lactobacilli levels after ingestion of the probiotic bacterium Lactobacillus reuteri ATCC 55730 by straws or tablets. Acta Odontol Scand 64:314-318. doi:10.1080/00016350600801709

23. Nikawa H, Makihira S, Fukushima H, Nishimura H, Ozaki Y, Ishida K, Darmawan S, Hamada T, Hara K, Matsumoto A, Takemoto T, Aimi R (2004) Lactobacillus reuteri in bovine milk fermented decreases the oral carriage of mutans streptococci. Int J Food Microbiol 95:219-223. doi:10.1016/j.ijfoodmicro.2004.03.006

24. Beena-Divya J, Kulangara-Varsha K, Madhavan-Nampoothiri K, Ismail B, Pandey A (2012) Probiotic fermented foods for health benefits. Eng Life Sci 12:377-390. doi:10.1002/elsc.201100179

25. Bauer AW, Kirby WM, Sherris JC, Turck M (1966) Antibiotic susceptibility testing by a standardized single disk method. Am J Clin Pathol 45:493-496
26. Bian L, Molan AL, Maddox I, Shu Q (2011) Antimicrobial activity of Lactobacillus reuteri DPC16 supernatants against selected food borne pathogens. World J Microbiol Biotechnol 27:991-998. doi:10.1007/s11274-010-0543-Z

27. Tobajas M, Mohedano AF, Casas JA, Rodríguez JJ (2007) A kinetic study of reuterin production by Lactobacillus reuteri $P R O$ 137 in resting cells. Biochem Eng J 35:218-225. doi:10.1016/j. bej.2007.01.017

28. Beckers HJA, van der Hoeven JS (1982) Growth rates of Actinomyces viscosus and Streptococcus mutans during early colonization of tooth surfaces in gnotobiotic rats. Infect Immun 35:583-587

29. Gilmore KS, Srinivas P, Akins DR, Hatter KL, Gilmore MS (2003) Growth, development and gene expression in a persistent Streptococcus gordonii biofilm. Infect Immun 71:4759-4766. doi:10.1128/iai.71.8.4759-4766.2003

30. Asikainen S (2006). In vitro growth inhibition of periodontitisassociated bacteria by Lactobacillus reuteri. BioGaia Report EC034/R\&D Poster presented at: Anaerobe 2006 Boise, Idaho, USA. http://urn.kb.se/resolve?urn=urn:nbn:se:umu:diva-11227

31. Holz C, Alexander C, Balcke C, Moré M, Auinger A, Bauer M, Junker L, Grünwald J, Lang C, Pompejus M (2013) Lactobacillus paracasei DSMZ16671 reduces Mutans streptococci: a short-term pilot study. Probiotics Antimicrob Prot 5:259-263. doi:10.1007/ s12602-013-9148-9

32. Chuang LC, Huang CS, Ou-Yang LW, Lin SY (2011) Probiotic Lactobacillus paracasei effect on cariogenic bacterial flora. Clin Oral Invest 15:471-476. doi:10.1007/s00784-010-0423-9

33. Hsu CH, Chen YH, Wang YY, Lai DY, Hsieh FC (2008) Lactobacillus paracasei-containing product. Google Patents. http:// www.google.com/patents/US20080118444

34. Schaefer L, Auchtung TA, Hermans KE, Whitehead D, Borhan B, Britton RA (2010) The antimicrobial compound reuterin (3-hydroxypropionaldehyde) induces oxidative stress via interaction with thiol groups. Microbiology 156:1589-1599. doi:10.1099/ mic.0.035642-0 